methionyl-tRNA to ribosomes in the presence of the trinucleotide AUG. Thus Salas et al. suggest that factors $f 1$ and $f 2$ regulate the binding of the initiator $\mathrm{N}$-formylmethionyl- $t \mathrm{RNA}$ to the site in the ribosome normally occupied by the growing polypeptide chainthe so-called peptidyl site.

Further information about the part played by these factors has come from Lucas-Lenard and Lipmann (Proc. U.S. Nat. Acad. Sci., 57, 1050; 1967), who find that the chain initiator factors $f 1$ and $f 2$ are necessary for the initiation of synthesis of polyphenylalanine by an artificial initiator $\mathrm{N}$-acetylphenylalanine in an $E$. coli cell free system containing polyU as $m \mathrm{RNA}$ and low (4 mmolar) concentrations of $\mathrm{Mg}^{\mathrm{H}}$ ions. They conclude that factors $f 1$ and $f 2$ function in this simplified system as they do with natural $m$ RNAs and $\mathrm{N}$-formylmethionyl-tRNA.

The same workers suggest that the binding of $\mathrm{N}$-acetylphenylalanyl-sRNA to the peptidyl site depends on the presence of guanosine triphosphate (GTP). In contrast, Thach and co-workers (Proc. U.S. Nat. Acad. Sci., 5\%, 759; 1967; and ibid., p. 1103) find that the binding of formylmethionyl- $t$ RNA to ribosomes in the presence of the codon AUG is independent of GTP, which led to the suggestion that the initiating aminoacyl-sRNA binds first to the aminoacyl-sRNA binding site in ribosomes under the influence of factors $f 1$ and $f 2$ and that GTP is involved in its subsequent transfer to the peptidyl site of the ribosome. Whatever the explanation, these experiments are taken to imply that under physiological conditions the formation of the initial peptide bond of a polypeptide requires the splitting of a molecule of GTP.

One of the two initiation factors scems also to stimulate the transeription of DNA. Revel and Gros (Biochem. Biophys. Res. Commun., 2\%, 12; 1967) have isolatcd two factors, named $B$ and $C$, which are probably identical with $f 1$ and $f 2$. Both of them are required for chain initiation and, in the presence of ribosomes, factor $C$ (but not $B$ ) stimulates T4 phage $m$ RNA synthesis from phage DNA templates. By stimulating initiation, the chain initiating factors of $E$. coli promote the attachment of ribosomes to $m \mathrm{RNA}$ and thus have the secondary effect of stimulating the release of nascent $m$ RNA from DNA templates (see Nature, 214, 228; 1967) and of enhancing DNA transeription.

The triplet AUG is not, however, the only codon for initiation with N-formylmethionine. It has been shown by Ghosh et al. (J. Mol. Biol., 25, 275; 1967) that GUG and GUA also initiate polypeptido synthesis with $\mathrm{N}$-formylmethionine in $E$. coli. The fact that most $E$. coli proteins have either methionine, alanine or serine at the $N$ terminal position has suggested that there may be some mechanism for removal of the $\mathrm{N}$-formyl group or the $\mathrm{N}$-formylmethionyl residue. In support of this, Weissbach and Redfield (Biochem. Biophys. Res. Commun., 27, 7 ; 1967) report briefly the presence of an enzymo in $E$. coli which removes the formyl group from $\mathrm{N}$-formylmethionine but not from other $\mathrm{N}$-formyl armino-acids.

It is surprising that despite all this information on chain initiation in bacterial cells, little is known about this process in the cells of higher organisms, although there is every reason to expect that the mechanism will be found to be basically similar.

\section{Cystine in Cell Division}

\section{from a Correspondent in Molecular Biology}

A NEW enzyme has been prepared by Sakai (J. Biol. Chem., 242, 1458; 1967), which appears to bo intimately involved in the control of cell division. The "spindle protein" of sea-urchin eggs is an aggregate of small sub-units in the form of microtubules. Cleavage is apparently brought about when it interacts with a contractile protein in the cell cortex which is responsible for the constriction which precedes cell division. The interaction was earlier reported by Sakai to take the form of an electron exchange, in which cysteine residues from the contractile protein are oxidized, and eystines from the cortical protein reduced. Sakai has now found that this exchange process is catalysed by an enzyme which he has isolated from the cytoplasmic extract.

The fraction containing all the detectable activity was isolated by gel filtration or electrophoresis and appears to consist of essentially pure enzyme of molecular weight 13,500 . As isolated, the enzyme contains a single cystcine residue, but on reduction with mereaptoethanol two further thiol groups (which are evidently very easily re-oxidized) appear, and the activity at the same time doubles. The most remarkable feature of this enzyme, however, is that it is associated with a decaribonucleotide, which is necessary for activity. This makes up some 3,000 of the total molecular weight, and has three residues each of cytosine and guanine and two each of adenine and uracil. It may be surmised that this is a paired oligonucleotide, and indeed it is found to be resistant to pancreatic ribonuclease, as such a species should be, but labile to the exonuclease from snake venom. The protein and the oligonucleotide have been separately isolated, and can be recombined with substantial recovery of the activity. It is not clear whether the decanucleotide is actually involved in the active site of the enzyme or in some way determines the conformation. Sakai suggests that the availability of the nucleotide may constitute a control mechanism. It may be recalled that another system which contains an oligonucleotide of no clearly defined function is the cytochrome $b_{2}$ studied by Morton and co-workers.

The function of the new enzyme is curiously reminis. cent of the factor found by Anfinsen and his associates to occur in the microsome fraction of mammalian cells, which catalyses the refolding of proteins to their native conformation. When disulphide bridges of proteins are reduced, and allowed to reoxidize, "incorrect" proteins can be formed, in which the half-cystines are mis-paired. Such forms are energetically unfavourable in relation to the native state and will slowly revert to their native conformation by disulphide interchange. The enzyme evidently functions by promoting electron exchange, thus making the cystines more labile and allowing the protein to search more rapidly for its lowest energy conformation. In a recent article (Fuchs et al., J. Biol. Chem., 242, 398; 1967) it was established that the enzyme possesses three half-cystine residucs, one of which must be in the reduced form for activity. The enzyme (like the seaurchin protein) is therefore activated by the reducing agent, mercaptoethanol. It seems likely that both enzymes function in a similar manner, by acting as intermediates in a reduction-oxidation chain. 